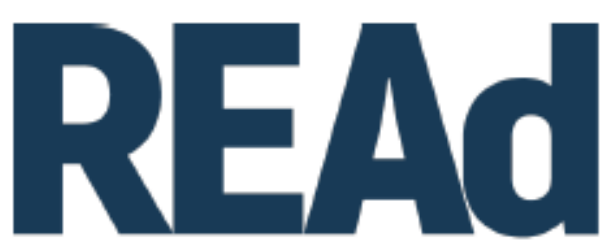

Revista Eletrônica de Administração

\title{
A PRODUÇÃO DE CONHECIMENTO EM ADMINISTRAÇÃO: FORTALECENDO A RELAÇÃO ENTRE TEORIA E PRÁTICA
}

\section{Guilherme Dornelas Camara ${ }^{1}$}

http://dx.doi.org/10.1590/1413-2311.276.97842

Com esse Editorial, abro o primeiro número como Editor-chefe da REAd Revista Eletrônica de Administração, tarefa que assumo nos próximos 2 anos. Nesse período, terei o desafio de cumprir com os critérios de avaliação da CAPES e os requisitos de bases de dados, como SciELO, em um contexto de poucos recursos para o financiamento da pesquisa e sua divulgação. Além disso, será necessário manter o alto padrão que a Revista conquistou entre 2017 e 2019, quando Maria Ceci Misoczky foi sua Editora. Sob sua editoria, a REAd voltou a ser um periódico de destaque no cenário nacional e tem atraído cada vez mais autores interessados em divulgarem seus trabalhos na Revista.

As estatísticas consolidadas de 2019 ilustram a nova dimensão da REAd. Desde 1 de janeiro até o momento em que escrevo essas linhas, recebemos 349 submissões de trabalhos. Mantido esse ritmo até o final do ano, a REAd terá recebido mais de 1 artigo para avaliação por dia. Em tempos de questionamento sobre a Academia e o conhecimento por ela produzido, de negligência oficial à pesquisa e à Universidade Pública, e do elogio às crenças pessoais e às emoções ante fatos e conhecimento, esse quantitativo deve ser celebrado.

Cumprimento a todos autores que enviaram suas contribuições para a REAd pelo compromisso com o conhecimento produzido em nosso campo; como afirma Bajtín (1997, p. 10), filósofo da linguagem, “[p]ois que penso, devo pensar sinceramente, a sinceridade é um dever do pensamento". Independente da onto-epistemologia em que um acadêmico se inscreva, a prática fundamental da pesquisa - desde estudar, formular

\footnotetext{
${ }^{1}$ Universidade Federal do Rio Grande do Sul - Escola de Administração; Porto Alegre - RS (Brasil); http://orcid.org/0000-0001-5021-9535; guilherme.dornelas@ufrgs.br
} 
um problema, executar sua investigação, organizar dados, até apresentar seus resultados de modo claro - exige compromisso de quem deseja conhecer algo novo, compromisso esse que Bajtín (1997, p. 10) chama de 'dever ser': “o dever ser surge apenas na correlação da verdade, significativa em si mesma, com nosso autêntico ato de conhecimento, e esse momento de correlação é um momento historicamente único, é um ato sempre individual, que não repercute em absoluto a significância teórica de um juízo".

Dos 349 trabalhos submetidos à REAd em 2019, 31 foram aprovados e publicados, ou seja, aproximadamente $9 \%$. Uma razão para isso é a mudança na linha editorial, que passou a aceitar ensaios e exige que os trabalhos práticos tenham uma forte articulação teórico-empírica, com contribuições para a prática, mas também para o conhecimento sobre o tema (MISOCZKY, 2019). Outra razão é o rigor e o compromisso dos avaliadores que contribuíram com a Revista nesse ano. Ler seus pareceres é uma oportunidade ímpar de aprendizado. Esses fatores possibilitam que a REAd qualifique a sua contribuição para a produção do conhecimento em Administração, reforçando os vínculos entre teoria e prática no campo de conhecimento.

A necessidade de aprofundar essa relação tem a ver com a urgente passagem de uma consciência ordinária para uma consciência reflexiva frente à realidade, como aponta Sánchez Vázquez (2003). A teoria permite explicar a realidade e suas transformações, mas aquele que produz teoria, ao fazê-lo, o faz situadamente; julga que suas ideias são capazes de oferecer uma explicação para um conjunto determinado de relações sociais, sem, no entanto, dar-se conta de que ele mesmo transpõe para seu quefazer relações sociais em que vive. Em comum, os textos que compõem esse terceiro número de 2019 da REAd consideram as transformações pelas quais a realidade organizacional passa e o agravamento da crise econômica. Seus autores nos convidam a pensar sobre o contemporâneo e geram novas contribuições tanto para a prática, quanto para a teoria, em uma multiplicidade de perspectivas que reforça o traço interdisciplinar de nosso campo de conhecimento.

Sánchez Vázquez usa a etimologia do termo 'prática', remontando ao grego antigo, para propor uma diferença entre 'prática' e 'práxis'. Práxis significa a “ação de levar algo a cabo, mas uma ação que tem fim em si mesma e que não cria um objeto alheio a quem age ou à sua atividade" (SÁNCHEZ VÁZQUEZ, 2003, p. 28), em outras palavras, a unidade entre o pensamento e ação: “[a] destruição da atitude própria da consciência ordinária é condição indispensável para superar toda consciência 
mistificada da práxis e elevar-se a um ponto de vista objetivo, científico, sobre a atividade prática do homem. Só assim podem se unir conscientemente o pensamento e a ação". Se não constituem em si mesmo práxis, os onze artigos desse número são mais um passo no fortalecimento da relação entre prática e teoria, condição elementar para a práxis, voltando-se, de alguma maneira, para contradições de instâncias da realidade.

Os três primeiros artigos abordam políticas públicas no campo dos direitos sociais. Considerando o contexto de aceleração tecnológica e aprofundamento da crise do capital, Camila Furlan da Costa e Sueli Maria Goulart Silva analisam o "Novo neoliberalismo acadêmico e o ensino superior no Brasil". As autoras apropriam-se da formulação de José Francisco Puello-Socarrás para abordar a articulação entre as políticas de ampliação do acesso e de incentivo à inovação nas universidades públicas brasileiras como uma transformação de políticas neoliberais, adquirindo novas características em função das mudanças recomendadas por organismos internacionais.

O segundo artigo, "Novo modelo e velhos problemas: a criação de um serviço social autônomo sob a ótica da eficiência", objetiva analisar os desdobramentos da criação do Instituto Hospital de Base do Distrito Federal (IHBDF) sob a ótica da eficiência do gasto com recursos humanos. Bruno Henrique Souza de Andrade e Andréa de Oliveira Gonçalves demonstram que a implantação de um novo modelo de gestão não superou problemas estruturais, como a ineficiência e a insuficiente oferta de serviços de saúde no Distrito Federal.

Fernanda Stringassi de Oliveira e Maria Beatriz Machado Bonacelli também abordam o tema da eficiência, mas nas organizações públicas de pesquisa do Brasil. Low efficiency in the use of research and development resources in Brazilian public research organizations: causal chains analysis adota o Planejamento Estratégico Situacional de Carlos Matus para avaliar o jogo social em que o gestor público de Pesquisa e Desenvolvimento atua e pensar em alternativas que superem a escassez de recursos e a ineficácia das políticas públicas do setor.

O contexto de escassez de recursos e dificuldades para a efetividade do setor público são decorrentes do agravamento da crise do capital. A ela coaduna-se a instabilidade política que o País vive desde 2015. No quarto artigo do número, Márcia Formiga, Claudio Marcelo Barros, Nathiele de Jesus Cezário e Luciano Marcio Scherer avaliam $O$ efeito da incerteza política no desempenho e valoração das companhias abertas brasileiras. Focando nos anos de 2014 a 2016, os autores destacam que o nível 
elevado de incerteza política do País alcançou a atividade econômica na forma de queda de desempenho e destruição do valor de mercado de empresas brasileiras.

Em endividamento de operadoras de planos de saúde da modalidade autogestão e regulação da saúde suplementar, Ewerton Alex Avelar, Antônio Artur de Souza, Hudson Fernandes Amaral e Stephanie Torres Reyes analisam os determinantes do endividamento das operadoras de planos de saúde, modalidade autogestão, sob a perspectiva da regulação da Agência Nacional de Saúde Suplementar (ANS). A principal variável observada foi a proporção de planos antigos da operadora. Também foram consideradas significantes as relacionadas ao porte, à idade média dos beneficiários e à região de atuação.

O sexto artigo do número, Global Buzz: uma meta-análise, propõe uma metaanálise da relação do global buzz, na criação do conhecimento e da inovação. Carla Cristina da Silva, Marcelo Moll Brandão e Luiz Antônio de Camargo Guerrazzi apontam que houve um aumento substancial de pesquisas que reconhecem que a aquisição de conhecimento de empresas aglomeradas se processa por via de interações deliberadas com outros atores fora da concentração de empresas. Os autores acreditam que o aprendizado e o desempenho de empresas aglomeradas podem contribuir para mudar a visão do campo e a compreensão de suas dinâmicas local e global.

A relação entre investimento em propaganda e o valor da firma: uma revisão sistemática e uma agenda de pesquisa para futuros estudos, de Ricardo Saraiva Frio, Thiago dos Santos Glasenapp, Rodrigo Heldt Silveira, Fernando Bins Luce, apresenta uma revisão da relação entre investimento em propaganda e o valor da firma. Os autores encontraram efeitos positivos da comunicação no valor da firma. Os autores propõem também uma agenda para pesquisas futuras, dada a escassez de trabalhos sobre o tema no Brasil.

Sánchez Vázquez (2003) afirma, no estudo da práxis, que a prática social deve ser o seu critério de verdade. Os últimos quatro artigos desse número abordam distintas frentes da prática social, com vistas à transformação da realidade, e nos inspiram a novas perspectivas na Administração. Comunalidad y transmodernidad en las prácticas organizativas de la Red de Huertos Educativos en México, o oitavo artigo do número, analisa as formas de conhecimento produzido a partir das práticas organizacionais de grupos sociais autônomos que seguem princípios comunitários. Giovanna Mazzotti Pabello e Kay Nicté Nava Nasupcialy articulam categorias propostas por Esteva e Dussel, para compreender os princípios que articulam o coletivo 
independente da rede de hortas educacionais e comunitárias de Xalapa (RHEC), Veracruz, México.

Romário Rocha Sousa, Rafael Diogo Pereira e Daniel Calbino escrevem Memórias do lixo: luta e resistência nas trajetórias de catadores de materiais recicláveis da ASMARE, em que analisam a luta e resistência vivenciados por catadores de materiais recicláveis, vinculados à Associação dos Catadores de Papel, Papelão e Material Reaproveitável (ASMARE), de Belo Horizonte (MG). Destacam o caráter contraditório do trabalho dos catadores: a geração de renda e a produção de sentidos do trabalho coexistem com a invisibilidade social e trabalho precário.

O décimo artigo, The people's bourough plan of action: a counter-project of insurgent citizenship, articula temas caros à Administração e ao Planejamento Urbano. Clarice de Oliveira, Camila Bellaver Alberti, Laura Boeck Silva e Gabriela Rosa Nodari adotam a teoria do planejamento insurgente para analisar um projeto desenvolvido por movimentos sociais, Instituto de Arquitetos do Brasil (IAB-RS) e pesquisadores da área que oferece assistência técnica a movimentos populares com o intuito de apoiar suas reivindicações e desejos sobre a cidade em que vivem. Essa instância possibilita criar um contra-plano relacionado à realização do direito à cidade.

Por fim, André Dias Mortari apresenta, no décimo primeiro artigo desse número,

A construção cotidiana da greve na UFRGS: o movimento contra as reformas no

final de 2016. Em um formato pouco usual na Administração, o autor, que participou ativamente dos movimentos, realizou uma pesquisa-militante a partir das reflexões de Henri Lefebvre. O estudo da greve, através da vida cotidiana permite reconhecer esse instrumento de luta da classe trabalhadora como lugar de transição, encontros, interações e conflitos.

\section{REFERÊNCIAS}

BAJTÍN, Mijaíl. M. Hacía una filosofia del acto ético: de los borradores. San Juan de Puerto Rico: Anthropos, 1997.

MISOCZKY, Maria Ceci. Trajetória recente e contribuições para o conhecimento em Administração, REAd, Porto Alegre, v. 25, n. 2, p. 1-3, ago.-set. 2019. Disponível em: <https://seer.ufrgs.br/read/article/view/95321> Acesso em 29 out. 2019

SÁNCHEZ VÁZQUEZ, Adolfo. Filosofía de la práctica. 1 ed. México, D. F.: Siglo XXI, 2003. 